\title{
Assessment of Induction, Recovery, Agitation upon Awakening, and Consumption with the Use of two Brands of Sevoflurane for Ambulatory Anesthesia
}

\author{
Cíntia Reina Grisan Tomal ${ }^{1}$, Ana Gabriela Padua Dias da Silva ², Américo Massafuni Yamashita, TSA ${ }^{3}$, \\ Pamela Vieira de Andrade ${ }^{4}$, Márcia Tamiko Hirano ${ }^{4}$, Maria Angela Tardelli, TSA ${ }^{5}$, Helga Cristina Almeida Silva 6
}

Summary: Tomal CRG, Silva AGPD, Yamashita AM, Andrade PV, Hirano MT, Tardelli MA, Silva HCA - Assessment of Induction, Recovery,
Agitation upon Awakening, and Consumption with the Use of two Brands of Sevoflurane for Ambulatory Anesthesia.

Background and objectives: Due to its pharmacological characteristics, sevoflurane is the ideal anesthetic for short-duration procedures. There are two brands of sevoflurane in the Brazilian market, Sevocris $₫$ and Sevorane $\AA$, with different formulations and packaging. The objective of this study was to assess whether there are differences between the two anesthetics regarding induction, maintenance, recovery, and consumption.

Methods: One hundred and thirty children were included, divided into two groups according to the brand used: Group 1 was assigned to sevoflurane Cristália ${ }^{\circledR}$ and Group 2 to sevoflurane Abbott ${ }^{\circledR}$. The following parameters were assessed: heart rate, systolic and diastolic blood pressure, fraction of inspired and expired sevoflurane, BIS values, tympanic temperature, induction and recovery time, agitation upon awakening measured by the PAED scale, and anesthetic consumption by weighing the vaporizers. Anesthesia was induced with 1 MAC and increased every three breaths at $0.5 \mathrm{MAC}$, up to $3 \mathrm{MAC}$.

Results: There was no difference between groups regarding the duration of the procedure, the anesthesia, and the parameters evaluated at induction. In Group 1, the number of children who required additional bolus of sevoflurane for anesthesia maintenance was higher than in Group 2 $(p<0.05)$. The fraction of inspired and expired sevoflurane at the end of the procedure was lower in Group 1 ( $p<0.001)$. Upon awakening, BIS value was lower in Group $1(p=0.045)$. Other parameters evaluated in recovery showed no difference between groups. The use of anesthesia was similar between groups.

Keywords: Ambulatory Surgical Procedures; Anesthetics, Inhalation/sevoflurane; Anesthesia, General; Quality of Health Care.

(๑2012 Elsevier Editora Ltda. All rights reserved.

\section{INTRODUCTION}

The properties of an ideal anesthetic for outpatient procedures include having smooth and fast onset of action; producing hypnosis, amnesia, analgesia; having no undesirable side effects; providing rapid recovery from anesthesia, in addition to postoperative residual analgesia, and be a good choice regarding cost/benefit $1,2,3$.

Received from the Anesthesiology, Pain, and Intensive-care Medicine Course, Universidade Federal de São Paulo (Unifesp), Brazil.

1. Anesthesiologist, Hospital Universitário Materno Infantil Presidente Dutra

2. Anesthesiologist, Hospital Seabra de Carvalho

3. Master in Anesthesiology, Assistant Professor of the Anesthesiology, Pain, and

Intensive-care Medicine Course, Escola Paulista de Medicina/Universidade Federal de São

Paulo (EPM-Unifesp)

4. Graduate student of the Anesthesiology, Pain, and Intensive-care Medicine Course,

EPM-Unifesp

5. PhD; Head of Discipline, Associate Professor, Anesthesiology, Pain, and Intensive-care

Medicine Course, EPM-Unifesp

6. PhD in Pathology, Universidade de São Paulo (USP); Postdoctorate at Unifesp; Coor-

dinator of CEDHIMA (Centre for Study, Diagnosis and Research of Malignant Hyperther-

mia); Instructor of Graduate studies, Unifesp

Submitted on March 20, 2011.

Approved on June 19, 2011

Correspondence to:

Dr. Américo Massafuni Yamashita

Rua Sousa Ramos, 144, apto 81

Vila Mariana

04120080 - São Paulo, SP, Brazil

E-mail:massafuni@uol.com.br
Among the volatile anesthetics, sevoflurane is less irritating to the respiratory tract and has low blood solubility, which results in rapid induction of anesthesia and recovery ${ }^{4,5}$. In the Brazilian market, sevoflurane is marketed by two laboratories, which have differences in the synthesis and storage of the anesthetic. It is speculated that these differences may also cause changes in the effectiveness, quality, and efficacy of anesthesia. Sevocris ${ }^{\circledR}$, by Cristália ${ }^{\circledR}$, has in its composition sevoflurane and 260 ppm of propylene glycol as a stabilizer and is packaged in amber glass (international patent). Sevorane $^{\circledR}$, by Abbott Laboratories ${ }^{\circledR}$, which holds a patent on the synthesis of sevoflurane, has in its composition $300 \mathrm{ppm}$ of water as a stabilizer. Currently, Sevorane ${ }^{\circledR}$ is packaged in a PEN (polyethylene naphthalate) plastic bottle. Both water and propylene glycol work as a stabilizer, preventing acid degradation of the product in the event of any compound behaving as Lewis acids ${ }^{6}$.

\section{OBJECTIVE}

The objective of this study was to evaluate in children the characteristics of inhalational anesthesia with sevoflurane marketed by two different laboratories (Cristália ${ }^{\circledR}$ and Abbott ${ }^{\circledR}$ ) for outpatient procedures. 


\section{METHODS}

After approval by the Ethics Committee of Hospital São Paulo (HSP) and informed consent signed by parents or guardians, 130 patients who underwent ophthalmic fundus examination under narcosis were included in this study at the IOP-GRAAC (Pediatrics Oncology Institute - Support Group for Children and Adolescents with Cancer). Patients were randomly divided into two groups, and the trial was performed on a double-blind basis. Two identical vaporizers, which identification was unknown to the anesthesiologist, were placed on the anesthesia machine by non-medical assistants according to the patient's group. One vaporizer contained Sevocris ${ }^{\circledR}$ and the other Sevorane $^{\circledR}$. The vaporizers were new and were only used with patients in this study. The treatment groups were identified only after all statistical analysis was completed.

Inclusion criteria for participants aged between 3 and 7 years, ASA P1 and P2, and painless procedures. Exclusion criteria included: obesity and/or malnutrition; procedures lasting more than two hours; patients with cognitive mental impairment; severe functional illnesses; the usage of neuroleptics, benzodiazepines, anticonvulsants, or other medications that could interfere with the minimum alveolar concentration (MAC) of sevoflurane; and patients undergoing chemotherapy.

\section{ANESTHESIA}

None of the children received premedication. They were referred to the operating room with their parents who accompanied the anesthesia induction until the child's loss of consciousness.

Patients were monitored with cardioscope (three leads), noninvasive blood pressure, pulse oximeter, gas analyzer, tympanic temperature, and analysis of Bispectral Index (BIS).

The values of heart rate (HR), systolic and diastolic blood pressure (SDBP), fraction of inspired and expired sevoflurane, and $\mathrm{O}_{2}$ saturation were recorded at times: 1 minute before induction, at the end of induction, 1 minute after the start of the procedure, every 5 minutes during anesthesia induction, at the time of anesthetic agent discontinuation, and upon awakening.

The expired concentration of $\mathrm{CO}_{2}$ and $\mathrm{BIS}$ values were recorded from the beginning of induction, and tympanic temperature after induction.

Inhalation induction through a facial mask was performed using Jackson-Rees system with sevoflurane and 100\% oxygen. The fresh gas flow was adjusted according to body weight range: $4 \mathrm{~L} \cdot \mathrm{min}^{-1}$ up to $15 \mathrm{~kg}, 6 \mathrm{~L} \cdot \mathrm{min}^{-1}$ from 15 to $20 \mathrm{~kg}$, and $8 \mathrm{~L}^{\mathrm{min}} \mathrm{m}^{-1}$ between 20 and $25 \mathrm{~kg}$. Induction was started with the inspired concentration of 1 MAC (2.5\%) of sevoflurane with 0.5 MAC increments every three breaths up to a maximum of 3 MAC.

The end of induction was defined as centralization of pupils, miosis, loss of ciliary reflex, and regular breathing. Only after this period, venipuncture was performed and and hydration was initiated with $4 \mathrm{~mL} \cdot \mathrm{kg}^{-1} \cdot \mathrm{h}^{-1}$ lactate Ringer's solution. The induction parameters were evaluated every 10 seconds and recorded on a special table. Anesthesia was maintained with spontaneous ventilation under mask and oropharyngeal cannula until the end of the procedure.

Anesthesia maintenance was performed using $60 \%$ oxygen and sevoflurane titrated to maintain BIS between 40 and 60. If blood pressure or HR increased $20 \%$ from baseline, or BIS level $>60$, or if decentralization of pupils occurred, a bolus of sevoflurane was administered with the value of the vaporizer increased to 3 MAC $(7.5 \%)$, maintaining this concentration for one minute. The values of blood pressure, HR, and BIS were recorded to analyze the effectiveness and hemodynamic events of sevoflurane bolus. After that minute, an inspired fraction which corresponded to the value being administered before the bolus was maintained - increased by $1 \%$.

Anesthetic consumption was assessed by weighing the vaporizers before and after anesthesia using a precision balance (Digimed KN-8000 DR). The amount of anesthetic consumed was calculated considering that sevoflurane density: $1.5 \mathrm{~g} \cdot \mathrm{mL}^{-1}$. Anesthesia time was considered from the beginning of induction with sevoflurane until the end of the surgical procedure. Time spent in the operating room (OR) was also recorded, measured from the moment of entrance to exit of the child from the OR.

At the end of the procedure, the vaporizer was turned off and ventilation was performed with $100 \%$ oxygen. The children were encouraged to respond to non-painful stimuli with verbal calls every ten seconds. The awakening time was considered from the time of sevoflurane withdrawal to the onset of the first response (first movement, eye opening, crying).

After awakening, the agitation was evaluated every ten minutes for an hour, in accordance to the Pediatric Anesthesia Emergence Delirium (PAED) scale used to quantify agitation ${ }^{7}$. Adverse events such as agitation, cough, nausea, and vomiting in different periods of anesthesia were recorded. Data were recorded on standardized tables for study by an observer who was not involved in the anesthesia procedure.

\section{Sample size}

It was initially planned a study with a sample size of 100 patients in each group. The study was initiated and when there was a total sample of 50 patients, an interim evaluation was carried out without breaking the randomization code. According to this analysis, it was found that a sample of 61 patients in each group would produce a power of $81 \%$ with a significance level of $5 \%$ that - compared to the equivalence between the mean recovery time of 8.2 minutes and a difference (range) between the means - would still result in an equivalence conclusion of $\pm 20 \%$. 


\section{STATISCAL ANALYSIS}

Qualitative variables were expressed as absolute number and percentage, and the comparison between the two groups for these variables was performed using the chi-square test; quantitative variables presenting normal distribution were expressed as mean \pm standard deviation, and the groups were compared using the Student's t-test. For cases in which the assumption of normality was not met, the quantitative variables were expressed as median, first quartile (Q1), third quartile (Q3), minimum and maximum values, and the comparison between groups was performed using the Mann-Whitney test. Box-plot graph was used to represent data distribution of quantitative variables according to the group. For comparison between the inspired and expired fractions within a group, the Wilcoxon signed-rank test was used.

Throughout the statistical analysis, it was adopted a significance level of $5 \%$. Therefore, the results showing a p-value of less than $5 \%(p<0.05)$ were considered statistically significant. All statistical analyses were performed using SPSS 16.0 software for Windows ${ }^{\circledR}$.

Table I - Demographic Data and Physical Status According to Group

\begin{tabular}{llll}
\hline & $\begin{array}{l}\text { Vaporizer 1 } \\
(\mathrm{n}=61)\end{array}$ & $\begin{array}{l}\text { Vaporizer 2 } \\
(\mathrm{n}=69)\end{array}$ & $\mathbf{p}$ \\
\hline Age (years) & & & 0.543 \\
$\quad \begin{array}{l}\text { Mean } \pm \text { DP } \\
\text { Gender } \mathrm{n}(\%)\end{array}$ & $4.3 \pm 1.2$ & $4.4 \pm 1.4$ & 0.487 \\
$\begin{array}{l}\text { Female } \\
\text { Male }\end{array}$ & $22(36.1 \%)$ & $29(42.0 \%)$ & \\
Weight (Kg) & $39(63.9 \%)$ & $40(58.0 \%)$ & \\
Mean \pm DP & $18.1 \pm 3.6$ & $18.5 \pm 3.8$ & \\
ASA n (\%) & & & $>0.498$ \\
I & $61(100.0 \%)$ & $68(98.6 \%)$ & \\
II & - & $1(1.4 \%)$ & \\
\hline
\end{tabular}

Table III - Data on Time to Loss of Ciliary Reflex According to Groups

\begin{tabular}{llll}
\hline & $\begin{array}{l}\text { Vaporizer 1 } \\
(\mathrm{n}=61)\end{array}$ & $\begin{array}{l}\text { Vaporizer 2 } \\
(\mathrm{n}=69)\end{array}$ & $\mathbf{p}$ \\
\hline $\begin{array}{l}\text { Time to loss of Ciliary } \\
\text { reflex (sec) }\end{array}$ & & & 0.117 \\
$\quad \begin{array}{l}\text { median (Q1-Q3) } \\
\text { minimum-maximum }\end{array}$ & $52(47-60)$ & $50(42-57)$ & \\
$\begin{array}{l}\text { Fraction of inspired sevo } \\
\text { at ciliary reflex loss (\%) }\end{array}$ & $\mathrm{n}=52$ & $\mathrm{n}=59$ & 0.824 \\
$\quad \begin{array}{ll}\text { median (Q1-Q3) } \\
\text { minimum-maximum }\end{array}$ & $6.8(6.1-7.4)$ & $6.8(5.7-7.4)$ & \\
$\begin{array}{l}\text { Fraction of inspired sevo } \\
\text { at ciliary reflex loss (\%) }\end{array}$ & $\mathrm{n}=52$ & $\mathrm{n}=59$ & 0.326 \\
$\quad \begin{array}{l}\text { median (Q1-Q3) } \\
\text { minimum - maximum }\end{array}$ & $5.3(3.9-6.4)$ & $5.0(4.1-5.9)$ & \\
\hline
\end{tabular}

Sevo: Sevoflurane; Q1: first quartile (25\% of values); Q3: third quartile $(75 \%$ of values).

\section{RESULTS}

The groups were identified after the statistical analysis and revealed that vaporizer 1 (Group 1) was filled with Sevocris ${ }^{\circledR}$, Cristália Laboratory ${ }^{\circledR}$, and vaporizer 2 (Group 2) with Sevorane $^{\circledR}$, Abbott Laboratories ${ }^{\circledR}$.

As seen in Table I, the two groups were homogeneous for age, gender, weight, and physical status (ASA) $(p>0.05)$. The length of time spent in the OR, for anesthesia and procedure, did not differ between groups $(p>0.05)$ (Table II).

Table III shows that data related to the loss of ciliary reflex during induction were homogeneous between groups $(p>0.05)$.

Figure 1 shows a percentage graph of the patients who maintained the ciliary reflex over time. There was no significant difference.

The groups were homogeneous $(p>0.05)$ for time of centralization of pupils and miosis, with a median of 226 and 248 seconds for vaporizers 1 and 2, respectively, (Figure 2). Group 2 showed greater variability at pupil centralization

Table II - Procedure Data According to Studied Groups

\begin{tabular}{llll}
\hline & $\begin{array}{l}\text { Vaporizer 1 } \\
(\mathrm{n}=61)\end{array}$ & $\begin{array}{l}\text { Vaporizer 2 } \\
(\mathrm{n}=69)\end{array}$ & $\mathbf{p}$ \\
\hline $\begin{array}{l}\text { Time spent in OR (min) } \\
\text { median (Q1-Q3) }\end{array}$ & $\begin{array}{l}22(19-26) \\
\text { minimum-maximum }\end{array}$ & $\begin{array}{l}23(18-45 \\
13-40\end{array}$ & 0.770 \\
$\begin{array}{c}\text { Anesthesia time (min) } \\
\text { median (Q1-Q3) }\end{array}$ & $11(9-14)$ & $12(9-17)$ & 0.266 \\
$\begin{array}{l}\text { minimum - maximum } \\
\text { Procedure time (min) }\end{array}$ & $6-34,2$ & $5-29$ & \\
$\quad \begin{array}{l}\text { median (Q1 - Q3) } \\
\text { minimum - maximum }\end{array}$ & $\begin{array}{l}6(4-9) \\
2-29\end{array}$ & $\begin{array}{l}7(4-12) \\
1-24\end{array}$ & \\
\hline
\end{tabular}

OR: operation room; Q1: first quartile (25\% of values); Q3: third quartile $(75 \%$ of values).

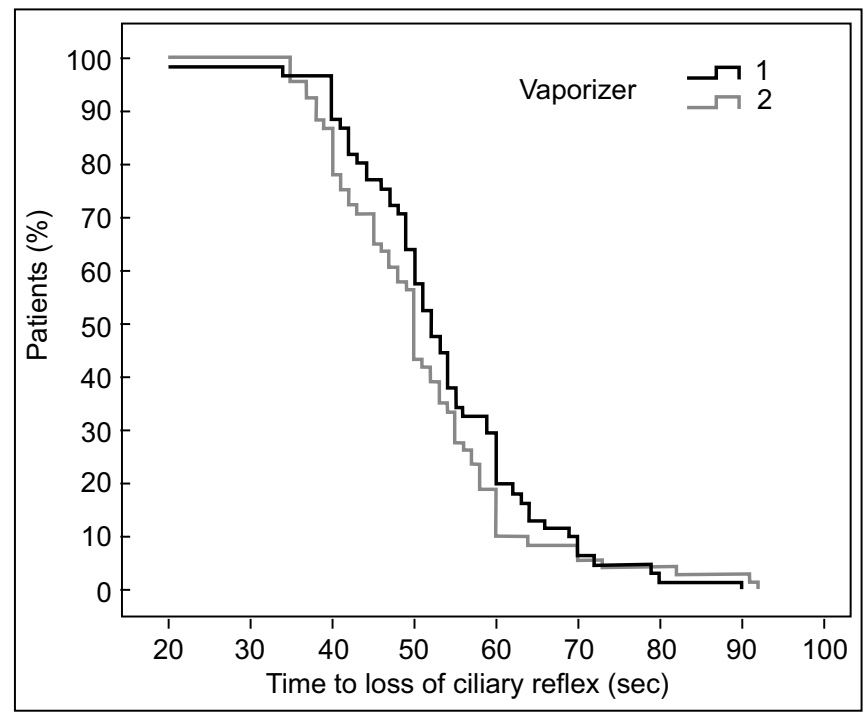

Figure 1 - Percentage of Patients who Presented Ciliary Reflex Over Time $(p>0.05)$. 
time, without significant difference. There was no significant difference in the inspired (5.9 and 5.6 for vaporizers 1 and 2 , respectively) and expired (5.0 and 4.6 for the vaporizers 1 and 2 , respectively) fractions of sevoflurane at the time of this parameter measurement.

During induction, the time to achieve regular breathing was similar in both groups, with a median of 189 (156-213) and 184 (138-230) seconds for groups 1 and 2, respectively. At this point, the fractions of inspired sevoflurane were equal in both groups (6.3\%), and the expired were similar (5.1 and 4.9 to vaporizer 1 and 2, respectively).

Table IV shows the BIS values and concentrations of sevoflurane at the end of induction. There was no significant

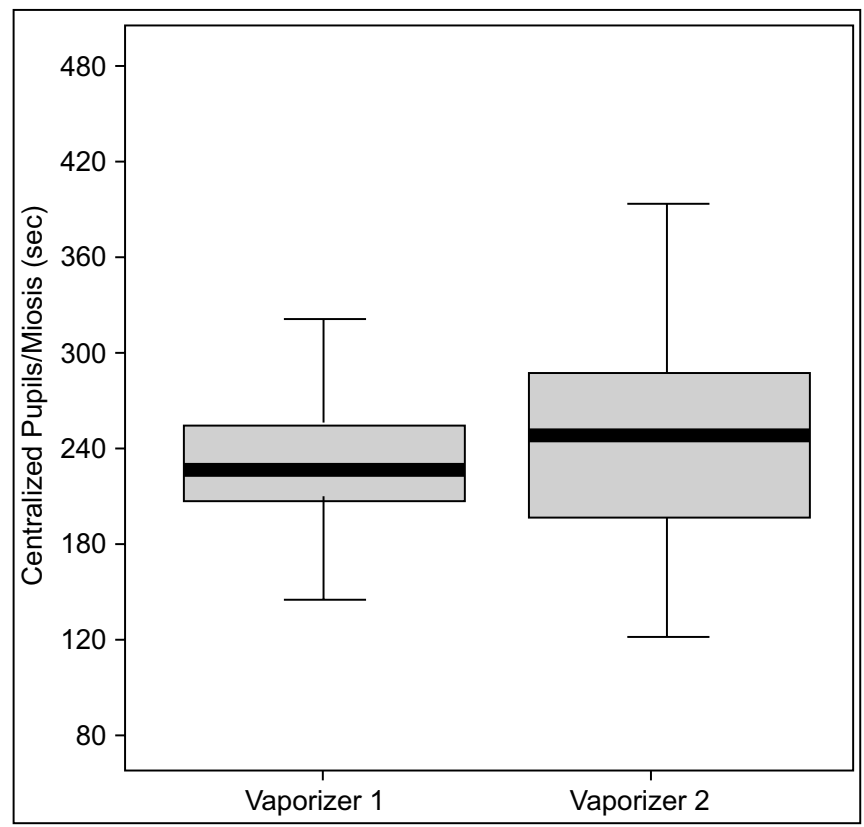

Figure 2 - Box-Plot of Centralized Pupils/Miosis According to Groups $(p>0.05)$. difference in BIS values or fractions of inspired and expired sevoflurane between Group 1 and Group 2. The total time of induction was similar in both groups $(p=0.525)$.

Figure 3 shows that the variability in the group with vaporizer 1 was higher than in the group with vaporizer 2 for both inspired and expired fraction of sevoflurane, with no significant difference.

Hemodynamic parameters and temperature are shown in Table V.

Events such as coughing and agitation during induction of anesthesia showed no difference between the two anesthetics studied (Figure 4).

As for the maintenance of anesthesia, the number of children anesthetized with vaporizer 1 requiring additional bolus was significantly greater than the number of children with vaporizer 2. However, the number of additional bolus was similar in both groups (Table VI).

Table IV - Anesthesia Parameters at the End of Induction

\begin{tabular}{llll}
\hline & Vaporizer 1 & Vaporizer 2 & $\mathrm{p}$ \\
\hline BIS & $\mathrm{n}=54$ & $\mathrm{n}=62$ & 0.124 \\
$\begin{array}{l}\text { median (Q1-Q3) } \\
\text { minimum-maximum }\end{array}$ & $36(28.5-42.5)$ & $33(29.5-39)$ & \\
$\begin{array}{l}\text { Fraction of inspired } \\
\text { sevo (\%) }\end{array}$ & $\mathrm{n}=57$ & $15-62$ & \\
$\begin{array}{l}\text { median (Q1-Q3) } \\
\text { minimum-maximum }\end{array}$ & $5.9(3.0-6.6)$ & $5.7(3.9-6.4)$ & \\
$\begin{array}{l}\text { Fraction of inspired } \\
\text { sevo (\%) }\end{array}$ & $\mathrm{n}=57$ & $2.7-7.7$ & \\
median (Q1-Q3) & $4.9(2.9-5.8)$ & $4.6(3.7-5.4)$ & \\
$\quad$ minimum-maximum & $2.0-7.1$ & $2.4-7.1$ & \\
$\begin{array}{c}\text { Total time of } \\
\text { induction (min) }\end{array}$ & $\mathrm{n}=61$ & $\mathrm{n}=69$ & 0.990 \\
$\quad \begin{array}{l}\text { median (Q1-Q3) } \\
\text { minimum-maximum }\end{array}$ & $4.0(3.3-4.3)$ & $4.1(3.2-4.8)$ & \\
\hline
\end{tabular}

BIS: bispectral index; Sevo: Sevoflurane; Q1: first quartile (25\% of values); Q3: third quartile $(75 \%$ of values).

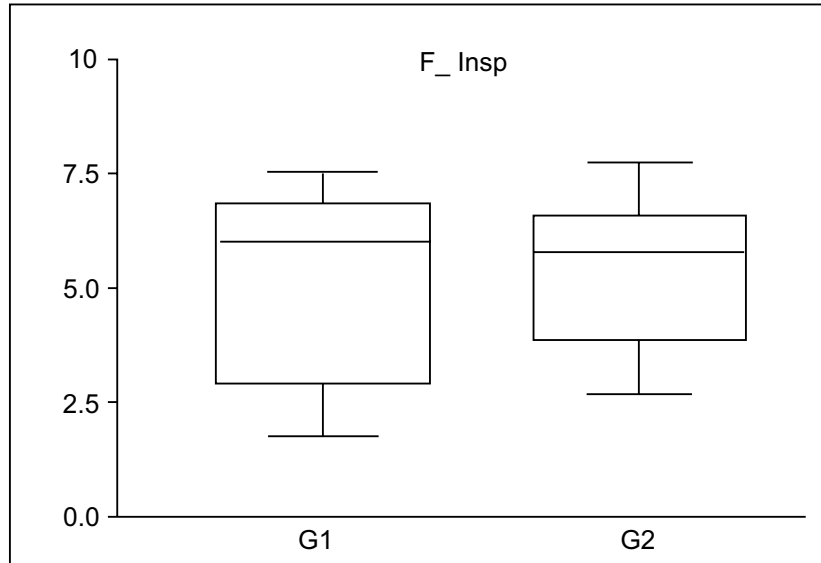

Figure 3A - Fraction Inspired of Sevoflurane $(p>0.05)$

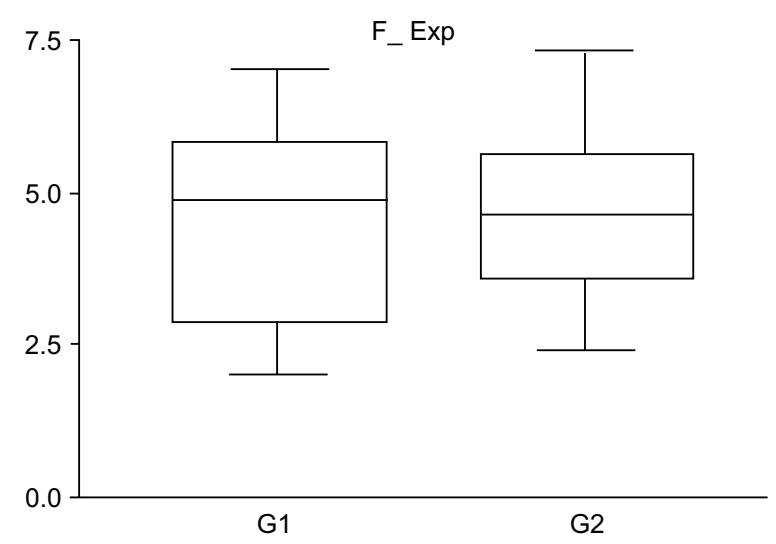

Figure 3B - Fraction Expired of Sevoflurane $(p>0.05)$.

Figure 3 - Box-Plot of the Inspired and Expired Fractions of Sevoflurane at the End of Induction According to Groups. 
Table VII shows that BIS values were higher in Group 1 at the time of sevoflurane discontinuation, and fractions of inspired and expired sevoflurane in this group were statistically smaller than those seen in Group 2, showing greater variability in results (Figure 5).

Data of HR, MAP, SDBP, and temperature at the time of sevoflurane discontinuation show that the groups were similar (Table VIII).

Upon awakening, the median BIS value was significantly higher in Group 2 with a value of 76 (74-79) compared with Group 2 value of 75 (73-78) $(p=0.045)$. Hemodynamic parameters were similar in both groups (Table IX).

There was no significant difference in the time of awakening, with a median of 5.9 (4.8 to 9.3) minutes in Group 2 and a median of 7.6 (5.7 to 9.8) minutes in Group $1(p=0.234)$.

Table V - Data on Hemodynamic Parameters at the End of Induction According to Groups

\begin{tabular}{clll}
\hline & Vaporizer 1 & Vaporizer 2 & $\mathrm{p}$ \\
\hline HR (bpm) & $\mathrm{n}=61$ & $\mathrm{n}=69$ & 0.302 \\
median (Q1-Q3) & $106(97-119)$ & $111(99-124)$ & \\
minimum-maximum & $69-152$ & $66-160$ & \\
MAP (mmHg) & $\mathrm{n}=59$ & $\mathrm{n}=66$ & 0.586 \\
median (Q1-Q3) & $71(61-78)$ & $72(64-81)$ & \\
minimum-maximum & $33-103$ & $47-94$ & \\
SAP (mmHg) & $\mathrm{n}=59$ & $\mathrm{n}=66$ & 0.458 \\
median (Q1-Q3) & $98(91-109)$ & $100(95-110)$ & \\
minimum-maximum & $76-125$ & $79-131$ & \\
DAP (mmHg) & $\mathrm{n}=59$ & $\mathrm{n}=66$ & 0.880 \\
median (Q1-Q3) & $52(43-62)$ & $52(47-59)$ & \\
minimum-maximum & $26-83$ & $31-81$ & \\
Temperature ( $\left.{ }^{\circ} \mathrm{C}\right)$ & $\mathrm{n}=61$ & $\mathrm{n}=68$ & 0.613 \\
median (Q1-Q3) & $36(36-37)$ & $36(36-37)$ & \\
minimum-maximum & $35-38$ & $35-37$ & \\
\hline
\end{tabular}

Q1: first quartile ( $25 \%$ of values); Q3: third quartile ( $75 \%$ of values).

HR: heart rate; MAP: mean arterial pressure; SAP: systolic arterial pressure; DAP: diastolic arterial pressure.

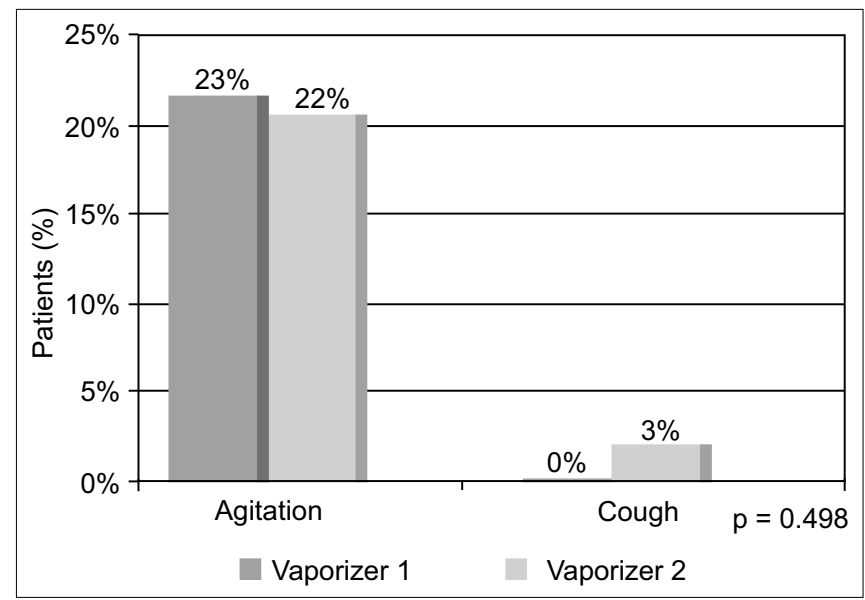

Figure 4 - Distribution of Children According to the Incidence of Agitation and Coughing at Induction According to Groups.
Regarding total anesthetic consumption in grams and milliliters per minute, no difference was observed between groups (Table X).

There was no significant difference in agitation assessed by PAED scale between groups at the evaluated times. Only one child from Group 2 who underwent laser had an increased index up to 60 minutes (Figure 6). The analysis of the PAED scale scores showed that at the time of awakening there was no significant difference between Group 1 that had a median score of 6 (4-8) and Group 2 that had a median score of 5 (3-7) $p=0.095$.

The graph shows the individual values, with circles representing patients in Group 1 and triangles those in Group 2. The traits between individual values represent the mean of each group.

Table VI - Distribution of the Number of Children who Received Additional Bolus of Sevoflurane and Laser Applications in both Groups

\begin{tabular}{llll}
\hline & Vaporizer 1 & Vaporizer 2 & $\mathrm{p}$ \\
\hline $\begin{array}{l}\text { Children with } \\
\text { additional bolus } \\
\text { Yes }\end{array}$ & & & 0.042 \\
$\quad$ No & $32(52.5 \%)$ & $24(34.8 \%)$ & \\
Number of & $29(47.5 \%)$ & $45(65.2 \%)$ & \\
$\begin{array}{l}\text { additional bolus } \\
1\end{array}$ & & & 0.187 \\
2 & $20(62.5 \%)$ & $16(66.7 \%)$ & \\
3 & $12(37.5 \%)$ & $6(25.0 \%)$ & \\
LASER & - & $2(8.3 \%)$ & \\
Yes & $1(1.6 \%)$ & $5(7.2 \%)$ & 0.213 \\
No & $60(98.4 \%)$ & $64(92.8 \%)$ & \\
\hline
\end{tabular}

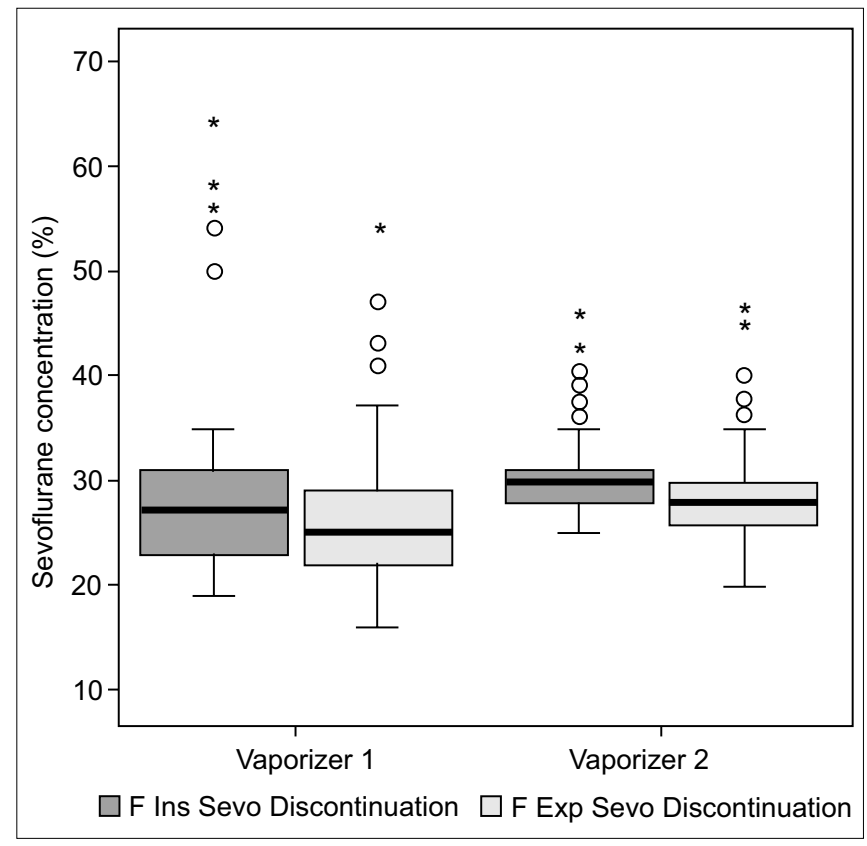

Figure 5 - Box-Plot of the Inspired and Expired Fractions of Sevoflurane at Anesthetic Discontinuation According to Groups ( $p>0.05$ ). 


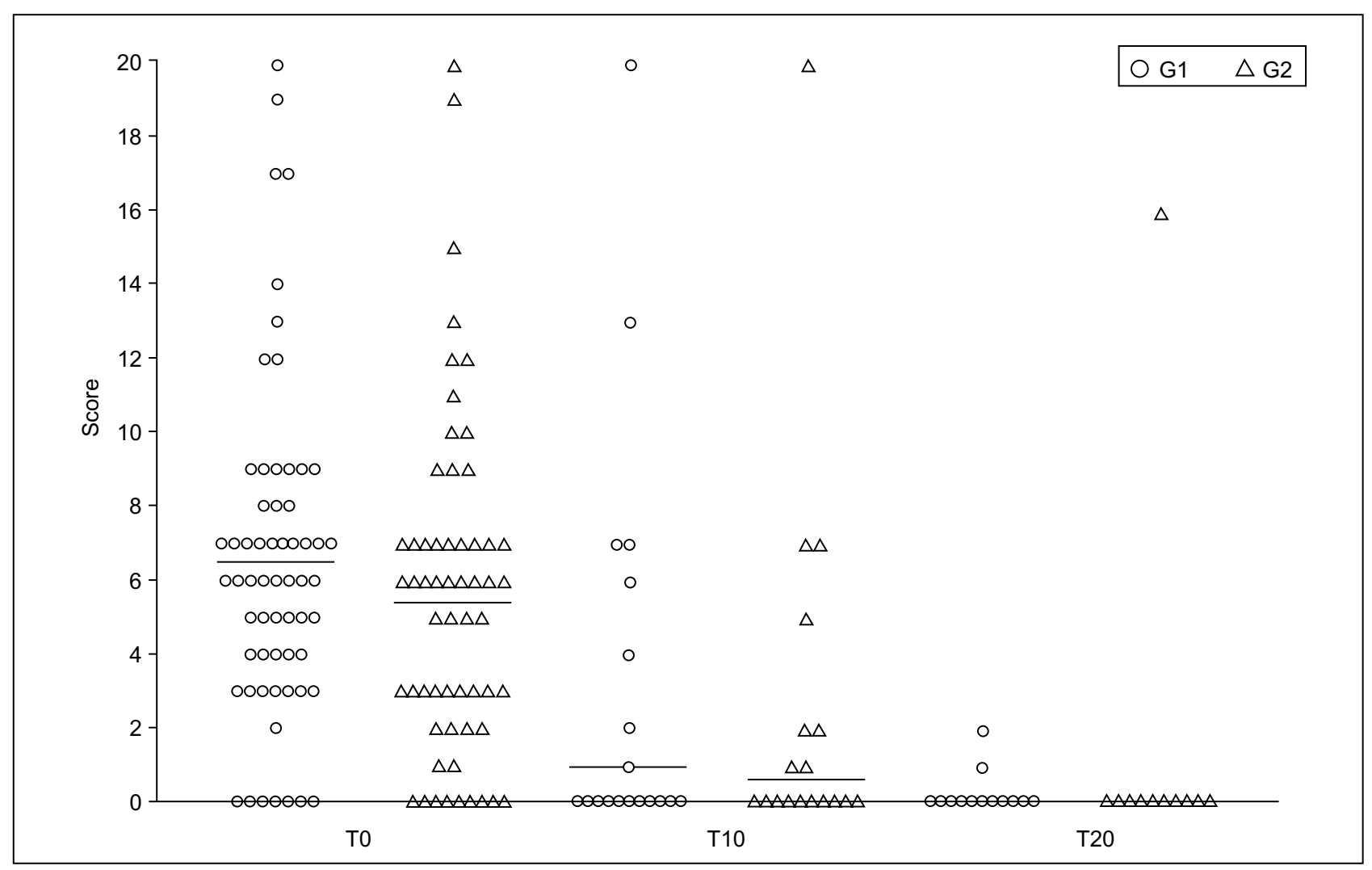

Figure 6 - Agitation Score According to the PAED Scale at Times Evaluated $(p>0.05)$.

Table VII - Data on Time of Sevoflurane Discontinuation According to Groups

\begin{tabular}{llll}
\hline & Vaporizer 1 & Vaporizer 2 & $\mathrm{p}$ \\
\hline BIS & $\mathrm{n}=60$ & $\mathrm{n}=69$ & 0.005 \\
median (Q1-Q3) & $50(43.5-55)$ & $45(39-52)$ & \\
minimum-maximum & $31-67$ & $22-62$ & \\
Vaporizer (\%) & $\mathrm{n}=61$ & $\mathrm{n}=69$ & 0.247 \\
median (Q1-Q3) & $3.0(3.0-3.5)$ & $3.0(3.0-3.0)$ & \\
minimum-maximum & $2.0-8.0$ & $2.5-8.0$ & \\
Fraction inspired of & $\mathrm{n}=61$ & $\mathrm{n}=69$ & $<0.001$ \\
sevo (\%) & & & \\
median (Q1-Q3) & $2.7(2.3-3.1)$ & $3.0(2.8-3.1)$ & \\
minimum-maximum & $1.9-6.4$ & $2.5-4.5$ & \\
Fraction expired of & $\mathrm{n}=61$ & $\mathrm{n}=69$ & $<0.001$ \\
sevo (\%) & & & \\
median (Q1-Q3) & $2.5(2.2-2.9)$ & $2.8(2.6-3.0)$ & \\
minimum-maximum & $1.6-5.4$ & $2.0-4.6$ & \\
ETCO $_{2}$ (mmHg) & $\mathrm{n}=11$ & $\mathrm{n}=14$ & 0.641 \\
median (Q1-Q3) & $24(20-27)$ & $28(23-28)$ & \\
minimum-maximum & $3-29$ & $3-29$ & \\
SatO & \\
median (Q) & $\mathrm{n}=61$ & $\mathrm{n}=69$ & 0.058 \\
minimum-maximum & $99(98-99)$ & $98(98-99)$ & \\
\hline
\end{tabular}

BIS: bispectral index; Sevo: Sevoflurane; $\mathrm{ETCO}_{2}$ : expired fraction of carbonic gas; $\mathrm{SatO}_{2}$ : oxygen peripheral saturation; Q1: first quartile (25\% of values); Q3: third quartile ( $75 \%$ of values).
Table VIII - Data on Hemodynamic Parameters and Temperature at Sevoflurane Discontinuation According to Groups

\begin{tabular}{clll}
\hline & Vaporizer 1 & Vaporizer 2 & $\mathrm{p}$ \\
\hline HR (bpm) & $\mathrm{n}=61$ & $\mathrm{n}=69$ & 0.194 \\
median (Q1-Q3) & $111(102-121)$ & $114(106-123)$ & \\
minimum-maximum & $70-146$ & $66-150$ & \\
MAP (mmHg) & $\mathrm{n}=60$ & $\mathrm{n}=68$ & 0.626 \\
median (Q1-Q3) & $71(62-75)$ & $68(65-73)$ & \\
minimum-maximum & $38-94$ & $48-94$ & \\
SAP (mmHg) & $\mathrm{n}=60$ & $\mathrm{n}=68$ & 0.727 \\
median (Q1-Q3) & $98.5(91-105.5)$ & $97(95-101)$ & \\
minimum-maximum & $63-119$ & $40-131$ & \\
DAP (mmHg) & $\mathrm{n}=60$ & $\mathrm{n}=68$ & 0.752 \\
median (Q1-Q3) & $52.5(44-59.5)$ & $50.5(46.5-56.5)$ & \\
minimum-maximum & $35-108$ & $33-100$ & \\
Temperature ( $\left.{ }^{\circ} \mathrm{C}\right)$ & $\mathrm{n}=60$ & $\mathrm{n}=68$ & 0.259 \\
median (Q1-Q3) & $36.3(35.7-36.6)$ & $36.1(35.8-36.5)$ & \\
minimum-maximum & $35.1-37.4$ & $34.8-37.2$ & \\
\hline
\end{tabular}

Q1: first quartile (25\% of values); Q3: third quartile (75\% of values).

HR: heart rate; MAP: mean arterial pressure; SAP: systolic arterial pressure; DAP: diastolic arterial pressure.

Adverse events observed during recovery were similar between groups and are presented in Table XI. Agitation was the most common adverse event in both groups. 
Table IX - Data on Hemodynamic Parameters upon Awakening of Sevoflurane According to Groups

\begin{tabular}{llll}
\hline Vaporizer 1 & Vaporizer 2 & $\mathrm{P}$ & \\
\hline HR (bpm) & $\mathrm{n}=61$ & $\mathrm{n}=69$ & 0.841 \\
median (Q1-Q3) & $100(88-114)$ & $100(93-110)$ & \\
minimum-maximum & $69-139$ & $71-148$ & \\
MAP (mmHg) & $\mathrm{n}=60$ & $\mathrm{n}=68$ & 0.245 \\
median (Q1-Q3) & $72.5(68-80)$ & $70(65-79)$ & \\
minimum-maximum & $47-95$ & $55-92$ & \\
SAP (mmHg) & $\mathrm{n}=60$ & $\mathrm{n}=68$ & 0.208 \\
median (Q1-Q3) & $102(96-108)$ & $98(96-104)$ & \\
minimum-maximum & $86-124$ & $79-122$ & \\
DAP (mmHg) & $\mathrm{n}=60$ & $\mathrm{n}=68$ & 0.195 \\
median (Q1-Q3) & $58.5(50-65)$ & $53.5(49.5-61)$ & \\
minimum-maximum & $38-84$ & $40-83$ & \\
\hline
\end{tabular}

Q1: first quartile (25\% of values); Q3: third quartile (75\% of values).

HR: heart rate; MAP: mean arterial pressure; SAP: systolic arterial pressure; DAP: diastolic arterial pressure.

Table X - Sevoflurano Consumption According to Groups

\begin{tabular}{llll}
\hline & $\begin{array}{l}\text { Vaporizer 1 } \\
(\mathrm{n}=61)\end{array}$ & $\begin{array}{l}\text { Vaporizer 2 } \\
(\mathrm{n}=69)\end{array}$ & $\mathrm{P}$ \\
\hline $\begin{array}{l}\text { Total anesthetic } \\
\text { consumption (g) }\end{array}$ & & & 0.580 \\
$\quad \begin{array}{l}\text { mediana (Q1-Q3) } \\
\text { mínimo-máximo }\end{array}$ & $\begin{array}{l}\text { 37.4 (31.3-47.4) } \\
\text { 23.3-162.6 }\end{array}$ & $\begin{array}{l}39.3(31.3-53.4) \\
16.8-91.2\end{array}$ & \\
$\begin{array}{l}\text { Anesthetic } \\
\left.\text { consumption (mL.min }{ }^{-1}\right)\end{array}$ & & & 0.626 \\
$\quad$ median (Q1-Q3) & $2.2(1.9-2.8)$ & $2.2(1.9-2.7)$ & \\
$\quad$ minimum-maximum & $1.2-15.3$ & $1.0-3.8$ & \\
\hline
\end{tabular}

Q1: first quartile (25\% of values); Q3: third quartile ( $75 \%$ of values).

\section{DISCUSSION}

The development of new inhalation agents, such as sevoflurane and desflurane, are meeting the needs of ambulatory surgery today. Sevoflurane is the agent that has ideal characteristics for use in pediatric outpatient procedures. Its properties include the absence of unpleasant odor, non-irritating to the airways, and low blood/gas partition coefficient, which allows rapid induction and recovery. There are three brands of sevoflurane in the world market with some differences in their formulations, such as the amount of water and packaging. The water added to sevoflurane works as a stabilizer, preventing the degradation of anesthetic by Lewis acids ${ }^{8}$. The packaging in suitable containers also aims to prevent degradation and can be supplied both in glass and PEN (polyethylene naphthalate) bottles or aluminum cylinders in flexible epoxy resin. In Brazil there are two brands available, Sevocris ${ }^{\circledR}$, by Cristália Laboratory ${ }^{\circledR}$ with propylene glycol as a stabilizer and packaged in amber glass bottles, and Sevorane ${ }^{\circledR}$ by Abbott ${ }^{\circledR}$, containing at least $300 \mathrm{ppm}$ of water and packaged in amber PEN bottles. The objective of this study was to evaluate if the difference in formulation and packaging of sevoflurane may
Table XI - Adverse Events at Recovery According to Groups

\begin{tabular}{|c|c|c|c|}
\hline Baseline & Vaporizer 1 & Vaporizer 2 & $p$ \\
\hline Agitation & $23(37.7 \%)$ & $22(31.9 \%)$ & 0.486 \\
\hline Cough & $5(8.2 \%)$ & $3(4.3 \%)$ & 0.473 \\
\hline Nausea & $1(1.6 \%)$ & $1(1.4 \%)$ & $>0.999$ \\
\hline Vomit & $1(1.6 \%)$ & $1(1.4 \%)$ & $>0.999$ \\
\hline \multicolumn{4}{|c|}{ Time: 5 minutes } \\
\hline Agitation & $10(16.4 \%)$ & $12(17.4 \%)$ & 0.880 \\
\hline Cough & $2(3.3 \%)$ & - & 0.218 \\
\hline Nausea & - & $1(1.4 \%)$ & $>0.999$ \\
\hline Vomit & - & $1(1.4 \%)$ & $>0.999$ \\
\hline \multicolumn{4}{|c|}{ Time: 10 minutes } \\
\hline Agitation & $5(8.2 \%)$ & $9(13.0 \%)$ & 0.374 \\
\hline Cough & - & - & - \\
\hline Nausea & - & - & - \\
\hline Vomit & - & - & - \\
\hline \multicolumn{4}{|c|}{ Time: 15 minutes } \\
\hline Agitation & $1(1.6 \%)$ & $5(7.2 \%)$ & 0.213 \\
\hline Cough & - & - & - \\
\hline Nausea & - & - & - \\
\hline Vomit & - & - & - \\
\hline \multicolumn{4}{|c|}{ Time: 20 minutes } \\
\hline Agitation & - & $3(4.3 \%)$ & 0.247 \\
\hline Cough & - & - & - \\
\hline Nausea & - & - & - \\
\hline Vomit & - & - & - \\
\hline \multicolumn{4}{|c|}{ Time: 25 minutes } \\
\hline Agitation & - & $1(1.4 \%)$ & $>0.999$ \\
\hline Cough & - & - & - \\
\hline Nausea & - & - & - \\
\hline Vomit & - & - & - \\
\hline \multicolumn{4}{|c|}{ Time: 30 minutes } \\
\hline Agitation & - & $1(1.4 \%)$ & $>0.999$ \\
\hline Cough & - & - & - \\
\hline Nausea & - & - & - \\
\hline Vomit & - & - & - \\
\hline \multicolumn{4}{|c|}{ Time: 35 minutes } \\
\hline Agitation & - & $1(1.4 \%)$ & $>0.999$ \\
\hline Cough & - & - & - \\
\hline Nausea & - & - & - \\
\hline Vomit & - & - & - \\
\hline \multicolumn{4}{|c|}{ Time: 40 minutes } \\
\hline Agitation & - & $1(1.4 \%)$ & $>0.999$ \\
\hline Cough & - & - & - \\
\hline Nausea & - & - & - \\
\hline Vomit & - & - & - \\
\hline
\end{tabular}

Values presented as number of patients and percentage.

be associated with differences in the characteristic of inhalational anesthesia and its consumption.

The results show that the demographic data, as well as those related to the anesthetic-surgical time, were homogeneous between groups (Tables I and II).

All pharmacodynamic parameters assessed throughout induction were not significantly different between groups. At the 
beginning of induction, although the time to lose ciliary reflex was similar between groups, this parameter tended to be faster in Group 2, but with no significant difference (Figure 1).

The end of the induction period, considered as the time of pupil centralization, miosis, and regular breathing, was similar between groups. The ratio of inspired and expired fraction of sevoflurane tended to be higher in Group 1 (Figure 3A and $3 \mathrm{~B}$ ). The total induction time was similar to other studies using the same technique of inhalational induction with progressive increases in sevoflurane concentration 9,10 .

Other parameters that could also alter the pharmacodynamic results due to changes in pharmacokinetics, such as $\mathrm{HR}$, blood pressure, and ventilation (assessed by $\mathrm{ETCO}_{2}$ and by the time to restore regular breathing), were similar between groups (Tables IV, V, and VII).

Adverse events such as coughing and agitation, which also interfere with the course of induction showed no difference between groups (Figure 4).

There are few studies evaluating the time to restore regular breathing during anesthesia induction. Kajal et al. ${ }^{11}$, using $6 \%$ sevoflurane associated with $50 \%$ nitrous oxide found a mean time of $41.76 \pm 20.41$ seconds to restore regular breathing, which is four times lower than that observed in this study. Even considering the use of nitrous oxide and a high initial concentration of sevoflurane used for induction, only the subjectivity evaluation of this parameter could explain the difference between the results of the two studies.

Data suggest that the vaporization of both anesthetics at the end of anesthesia induction was equally effective and had no reflection on pharmacodynamic parameters over this period. However, data analysis on maintenance and discontinuation of anesthesia suggests that over time the two anesthetics vaporization was different. During maintenance of anesthesia, a greater number of children in Group 1 required additional bolus of sevoflurane to maintain the same scheduled anesthesia, for the same intensity of pain stimulus in both groups (Table VI). At the end of anesthesia, on discontinuation of sevoflurane, despite the same concentration in the vaporizer dial of the two groups, the median fraction of inspired and expired sevoflurane were lower in Group 1 and consistent with the median value of BIS, which was greater, although within the adequate range for surgical hypnosis. Corroborating the hypothesis of change in anesthetic vaporization from vaporizer 1 , Figure 5 shows that this vaporizer dispersion, particularly of inspired fraction values, was greater than that of vaporizer 2 at the time of anesthetic discontinuation. These data suggest that the anesthetic vaporization in Group 1 was less efficient (Tables VI and VII).

The Brazilian Technical Standards (ABNT 13730/2010) admit a variation for the vaporization systems of up to $10 \%$ between the marking on the vaporizer dial and the inspired fraction of volatile agents, which could explain the observed difference between data of both groups ${ }^{12,13}$. The study design does not allow further conclusions about the differences observed.

The hemodynamic and ventilatory parameters that could alter the pharmacokinetics were homogeneous between groups both in the induction and the discontinuation of anesthesia (Table VII and VIII).

Although the children in Group 1 had required more additional boluses of anesthetic, it did not affect the consumption of sevoflurane. The same anesthetic consumption in both groups could be explained by the fact that among children who required additional bolus most received only one bolus (Table VI). The short duration of anesthesia may have also been insufficient to demonstrate the effect of change in anesthetic vaporization through consumption. The gravimetric method to assess anesthetic consumption is very accurate, for the volume consumed is calculated by anesthetic density and weighing the vaporizer ${ }^{14-16}$.

The recovery time for both groups was lower than in the studies by Lerman et al. ${ }^{2}$ (12.3 minutes) and Walker et al. ${ }^{9}$ (21.36 minutes), which can be explained by the absence of premedication, short duration of anesthesia, and small stimulus surgical procedures. Tardelli et al. ${ }^{10}$ found shorter recovery time (153.3 \pm 66.4 seconds) using a similar methodology. One possible explanation can be the maintenance of anesthesia with lower concentrations of sevoflurane, as surgical anesthesia was provided by regional block. However, the authors did not report the values of the inspired fraction of sevoflurane maintained during anesthesia to confirm this hypothesis.

Agitation was the most common adverse event during the recovery period. Upon awakening, $37.7 \%$ and $31.9 \%$ of children in Groups 1 and 2, respectively, showed agitation, but without significant difference between groups. These values were lower than the $47.2 \%$ seen by other authors in the recovery from tonsillectomies, a procedure considered to have higher risk of developing agitation during recovery from anesthesia with sevoflurane ${ }^{17}$. Both agitation and other adverse events such as coughing, nausea, and vomiting were more frequent in the first minutes of awakening, decreasing gradually (Table XI). Only one child in Group 2 showed agitation until the end of observation, which lasted 40 minutes.

Studies assessing the incidence of agitation upon awakening in children undergoing sevoflurane anesthesia are contradictory. This ambiguity may depend on the concept attributed to agitation or emergence delirium ${ }^{18}$. Sikich et al. ${ }^{7}$ validated the PAED scale to assess delirium, which should give consistency to the methodology of research on behavior change after anesthesia.

The incidence of agitation during recovery from anesthesia was similar in both groups according to scores on the PAED scale. Recently, some authors defined agitation as those situations where the score on the PAED scale is $>1017,19$. In this study, eight children in Group 1 and nine in Group 2 had scores above 10 upon awakening. Only four children had scores $>10$ (three for 10 minutes and one for 20 minutes during recovery). A study considering as agitation scores $>10$ on the PAED scale found incidence of $9 \%$, which is a value close to that found in this study 19 .

The use of two different brands of sevoflurane for ambulatory anesthesia with small nociceptive stimulation (examina- 
tion under narcosis and laser application in ophthalmology) showed no pharmacodynamic difference in induction, maintenance, recovery, and consumption. The difference in the inspired and expired fractions of sevoflurane, observed at the end of the procedure, had no effect on recovery and consumption of anesthetic. Although the study did not show a difference for short duration procedures, studies of longer duration procedures are needed to assess if this similarity remains.

\section{CONCLUSION}

In all parameters, the two anesthetics behaved similarly. There were no differences in induction time, consumption, side effects, and recovery time. 


\section{REFERÊNCIA/REFERENCES}

1. Nociti JR - Anesthesia inalatória: novas tendências, novos agentes. Rev Bras Anestesiol, 1994;44:295-296.

2. Lerman J Davis PJ, Welborn LG et al. - Induction, recovery, and safety characteristics of sevoflurane in children undergoing ambulatory surgery. Anesthesiology, 1996;84:332-340.

3. Nociti JR - Avaliação multicêntrica do sevoflurano. Rev Bras Anestesiol, 1998;48:29-36.

4. Strum D, Eger EI II - Partition coeficients for sevoflurane in human blood, saline, and olive oil. Anesth Analg, 1987;66:654-656.

5. Nathanson MH, Fredman B, Smith et al. - Sevoflurane versus desflurane for outpatient anesthesia: a comparison of maintenance and recovery profiles. Anesth Analg, 1995;81:1186-1190.

6. Baker MT - Sevoflurane: are there differences in products? Anesth Analg, 2007;104:1447-1451.

7. Sikich N, Lerman J-Development and psychometric evaluation of the pediatric anesthesia emergence delirium scale. Anesthesiology, 2004;100:1138-1145.

8. Kharach ED, Subbarao GN, Cromack KR et al. - Sevoflurane formulation water content influences degradation by lewis acids in vaporizers. Anesth Analg, 2009;108:1796-1802.

9. Walker SM, Haugen RD, Richards A - A comparison of Sevoflurane with Halothane for Paediatric Day Case Surgery. Anaesth Intens Care, 1997;25:643-649.

10. Tardelli MA, Iwata NM, Amaral JLG et al. - Influência do óxido nitroso na velocidade de indução e de recuperação do halotano e do sevoflurano em pacientes pediátricos. Rev Bras Anesteiol, 2001;51:273285.

11. Kajal N. Dedhia K N, Kudalkar A - Comparison of sevoflurane and halothane for induction of anaesthesia and laryngeal mask airway insertion in paediatric patients. Indian J Anaesth, 2004;48:465-468.

12. Fortis $E A F-O$ aparelho de anestesia. em: anestesiologia - princípios e técnicas, $3^{\text {a }}$ Ed, Porto Alegre, Artmed, 2004, pp 358-393.

13. Associação Brasileira de Normas Técnicas - Aparelho de anestesia: Seção de fluxo contínuo; Requisitos de desempenho e segurança. ABNT NBR 13730:2010, publicado em 31/08/2010.

14. Boldt J, Jaun N, Kumle B et al. - Economic considerations of the use of new anesthetics:a comparison of propofol, sevoflurane, desflurane, and Isoflurane. Aneth Analg, 1998;86:504-509.

15. Ekibom K, Assareh H, Anderson SE et al. - The effect of fresh gas flow on the amount of sevoflurane vaporized during 1 minimum alveolar concentration anesthesia for day surgery: a clinical study. Acta Anaesthesiol Scand, 2007;51:290-293.

16. Theidiraki A, Fassoulak A - Sevoflurane consmuption: laryngeal mask vs. tracheal intubation. Eur J Anesthesiol, 2008;25:607-609.

17. Aouad MT, Yazbeck-Karam VG, Nasr VG et al. - A single dose of propofol at the end of surgery for the prevention of emergence agitation in children undergoing strabismus surgery during sevoflurane anesthesia. Anesthesiology 2007;107:733-738.

18. Bortone L, Ingelmo P, Grossi S et al. - Emergence agitation in preschool children doubld- blind randomized, controlled trial comparing sevoflurane and isoflurane anesthesia. Pediatr Anesth, 2006;16:11381143 ,

19. Bryan YF, Hoke LK, Taghon TA et al. - A randomized trial comparing sevoflurane and propofol in children undergoing MRI scans. Pediatric Anesthesia, 2009;19:672-681. 